\title{
Hyperreflexia induced by XLR-11 smoke is caused by the pyrolytic degradant
}

\author{
Kyoko Hataoka ${ }^{1}$. Asuka Kaizaki-Mitsumoto ${ }^{1}$ Mika Takebayashi-Ohsawa ${ }^{2} \cdot$ Natsumi Hattori $^{1} \cdot$ Masahiko Funada $^{2}$. \\ Satoshi Numazawa'
}

Received: 8 February 2019 / Accepted: 17 April 2019 / Published online: 7 May 2019

(c) The Author(s) 2019

\begin{abstract}
Purpose Some of the synthetic cannabinoids, often found in recreational drugs of the herbal form, reportedly induce a generalized seizure in drug abusers immediately after smoking. However, it is still unclear what elicits the sensorimotor responses, particularly in the case of hyperreflexia or excitatory behavior during the synthetic cannabinoid exposure. The purpose of this study was to explore the mechanism underlying the hyperreflexia induced by smoke intoxication of XLR-11 [(1-(5-fluoropentyl)- $1 H$-indol-3-yl)(2,2,3,3-tetramethylcyclopropyl)methanone].

Methods Locomotor activity and body temperature of mice were measured using an implanted Nano-Tag device. The intensity of catalepsy was determined by the bar test. The extracellular dopamine levels in the nucleus accumbens and glutamate levels in the hippocampus were measured by in vivo microdialysis using electrochemical detector-coupled high-performance liquid chromatography and by in vivo enzyme-based biosensor method, respectively.

Results Mice exposed to the smoke of XLR-11 exhibited hyperreflexia at the very early phase, followed by hypothermia and catalepsy. The XLR-11 smoke contained XLR-11 and XLR-11 degradant at a ratio of approximately 1:25. Mice treated intraperitoneally with XLR-11 degradant at a dose comparable to the smoke inhalation experiment showed a hyperreflexic effect immediately after the treatment, but XLR-11 showed no such effect. The effects of XLR-11 degradant were significantly suppressed by pretreatment with $\mathrm{AM}-251, \mathrm{CB}_{1}$ receptor antagonist. Extracellular dopamine and glutamate levels showed no evidence of involvement in the XLR-11 degradant-induced hyperreflexia; on the other hand gabapentin, a GABAergic antiepileptic, significantly suppressed the enhanced locomotor activity.

Conclusions The hyperreflexic effect of XLR-11 degradant is mediated by the $\mathrm{CB}_{1}$ receptor and possibly by GABAergic function.
\end{abstract}

Keywords Synthetic cannabinoid $\cdot$ XLR-11 degradant $\cdot$ Microdialysis $\cdot$ Hyperreflexia $\cdot \mathrm{CB}_{1}$ receptor $\cdot$ GABAergic function

\section{Introduction}

Electronic supplementary material The online version of this article (https://doi.org/10.1007/s11419-019-00476-z) contains supplementary material, which is available to authorized users.

Asuka Kaizaki-Mitsumoto

asuka.0110@pharm.showa-u.ac.jp

1 Division of Toxicology, Department of Pharmacology, Toxicology and Therapeutics, Showa University School of Pharmacy, 1-5-8 Hatanodai, Shinagawa-ku, Tokyo 142-8555, Japan

2 Department of Drug Dependence Research, National Institute of Mental Health, National Center of Neurology and Psychiatry, 4-1-1 Ogawa-Higashi, Kodaira, Tokyo 187-8553, Japan
Since July 2014, when the crackdown on illegal drugs was strengthened by the decision to implement emergency measures to eradicate recreational drug abuse, all head shops selling such drugs in Japan have been closed. However, recreational drugs are still available through the Internet, and drug abuse has remained a serious social problem. Although the biological actions of these recreational drugs are poorly elucidated, some studies have attempted to clarify their psychoactive effects by intraperitoneal administration in animals $[1,2]$, but this does not reflect the actual abuse situation.

Synthetic cannabinoid drugs are available in various forms, such as bath salts and herbal incense. The herbal incense form, taken mainly by smoking [3], is 
particularly popular among young abusers [4]. XLR-11 [(1-(5-fluoropentyl)- $1 H$-indol-3-yl)(2,2,3,3-tetramethylcyclopropyl)methanone] is a synthetic cannabinoid and was found in recreational drugs of the herbal form [3] until around 2012, when it began being regulated globally [5].

XLR-11 has a cyclopropyl ring structure and is easily cleaved into a pyrolyzed compound, the so-called XLR-11 degradant, upon heating [6]. XLR-11 is reported to change its chemical structure to that of XLR-11 degradant by smoking [7]. However, no study has been published on the psychoactive effects of XLR-11 smoke or the XLR-11 degradant. The psychoactive effects of synthetic cannabinoids are mediated mainly through the $\mathrm{CB}_{1}$ receptor and generally include analgesia, hypothermia, and suppressed behavior. However, a person who abused a recreational drug product containing synthetic cannabinoids was found to show apparent excitatory behavior such as significant agitation and seizures [8].

We have reported that forced $\mathrm{CB}_{1}$ receptor activation was linked with the jumping induced by a pyrolyzed compound of UR-144, another synthetic cannabinoid possessing a cyclopropyl ring, in mice [9]. Reportedly, dopamine (DA) is involved in the synthetic cannabinoid JWH-250- and JWH-073-induced sensorimotor, neurological, and neurochemical responses, including seizures and aggressiveness, in mice [10]. Glutamate has been suggested to be involved in synthetic cannabinoid AM-2201-induced seizures [11]. Therefore, the excitatory action of synthetic cannabinoids may vary, and the mechanisms of action could differ. Our preliminary experiments indicated that XLR-11 was more potent than UR-144 in mice exposed to the smoke of these compounds. Accordingly, this study was designed to clarify the mechanism of excitatory action induced by synthetic cannabinoids with the cyclopropyl ring using XLR-11. We show that mice exposed to the pyrolyzed XLR-11 degradant produced by smoking exhibited abnormal behavior, including hyperreflexia, in a $\mathrm{CB}_{1}$-dependent manner, indicating that smoking of synthetic cannabinoids may increase sensorimotor effects including seizures and hyperreflexia.

\section{Materials and methods}

\section{Materials}

The research collaborator obtained XLR-11 (Fig. 1a), intended for use as an ingredient in the recreational drug product, from a recreational drug vendor in April 2012, before it was assigned the status of designated substance and subsequently classified as a narcotic substance by the Japanese government. The chemical structure of the compound was confirmed by nuclear magnetic resonance (ECX-500; JEOL, Tokyo, Japan) (NMR) analyses (Fig. S1a). The purity a<smiles>CC1(C)C(C(=O)c2cn(CCCCCF)c3ccccc23)C1(C)C</smiles>

C

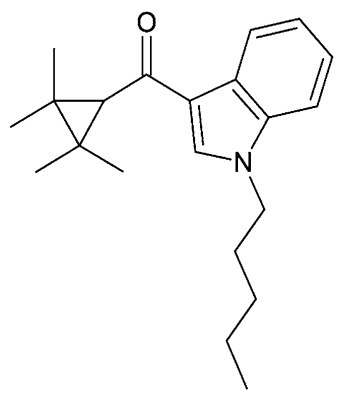

b<smiles>C=C(C)C(C)(C)CC(=O)c1cn(CCCCCF)c2ccccc12</smiles>

d

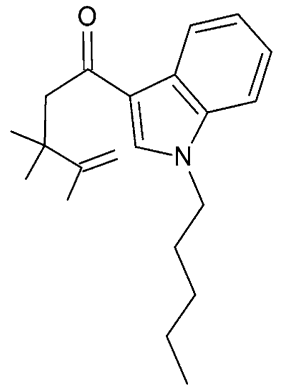

Fig. 1 Chemical structures of XLR-11 (a), XLR-11 degradant (b), UR-144 (c) and UR-144 degradant (d)

of the compound was estimated to be more than $95 \%$ by ${ }^{1}$ H-NMR. A 50-mg portion of XLR-11 was dissolved in acetone and mixed with $1 \mathrm{~g}$ of cut mint leaves. The solvent was evaporated to obtain the simulated herbal-type drug containing 5\% XLR-11. The XLR-11 degradant (Fig. 1b) was made by heating XLR-11 in a sealed glass tube at $300{ }^{\circ} \mathrm{C}$ for 10 min [9]. NMR analysis indicated that the compound obtained by heating was identical to the XLR-11 degradant and its content was more than 95\% (Fig. S1b). AM-251 and SCH23390 were purchased from Wako Pure Chemical Industries, Ltd. (Osaka, Japan); sulpiride and midazolam from Astellas Pharma Inc. (Tokyo, Japan); gabapentin from Tokyo Chemical Industry Co., Ltd. (Tokyo, Japan); butorphanol tartrate from Meiji Seika Pharma Co., Ltd. (Tokyo, Japan); medetomidine hydrochloride from Nippon Zenyaku Kogyo Co., Ltd. (Fukushima, Japan); SIB1757 from Merck KGaA (Darmstadt, Germany).

\section{Animals}

Male 8-week-old BALB/c mice were obtained from Sankyo Lab Service Corporation (Tokyo, Japan). Mice were housed in plastic cages placed in a temperature-controlled room $\left(22 \pm 1{ }^{\circ} \mathrm{C}\right)$ and maintained on a 12-h light-dark cycle with free access to food and water. 


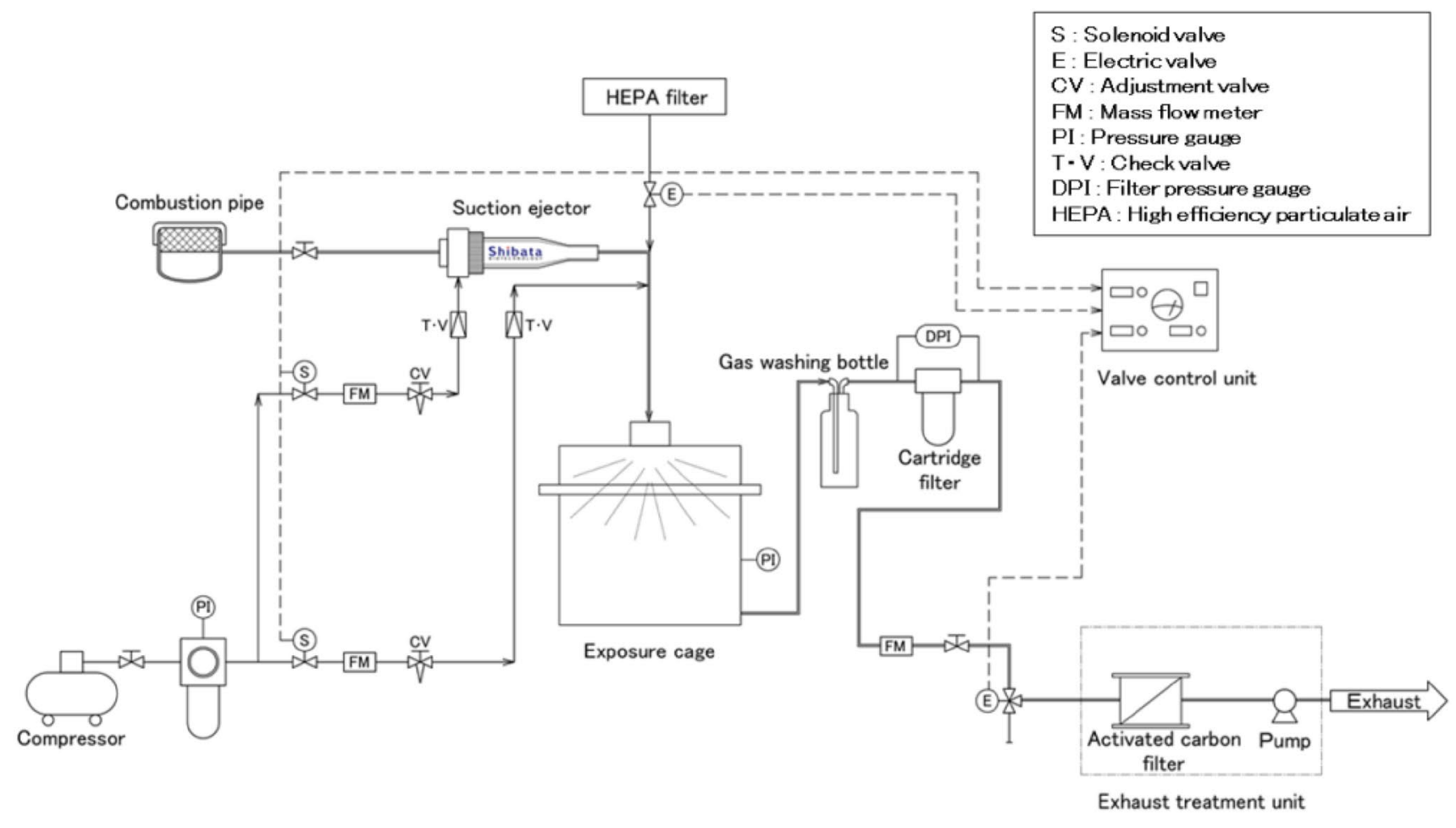

Fig. 2 Multipurpose inhalation cage unit

\section{Smoke exposure}

The mice were placed in a Multipurpose Inhalation Cage unit $\left(7018 \mathrm{~cm}^{3}\right.$, Shibata Biotechnology, Tokyo, Japan) (Fig. 2). A 0.5-g portion of mint herb containing XLR-11 or mint herb without XLR-11 (control) was burned in the pipe connected to the inhalation cage unit. The temperature of the burning herb measured by TR-W500 (KEYENCE Co., Ltd., Osaka, Japan) was approximately $300{ }^{\circ} \mathrm{C}$. Smoke was introduced into the chamber through an aerosol inlet. The exhaust flow rate was set at $18 \mathrm{~L} / \mathrm{min}$, the aspiration flow rate at $1 \mathrm{~L} / \mathrm{min}$, and the pressure of exposure cage at $-50 \mathrm{~Pa}$. The smoke from the pipe was diluted with room air (smoke to room air $=1: 17$ ) and drawn into the exposure cage at a flow rate of $18 \mathrm{~L} / \mathrm{min}$. The airflow was stopped $1 \mathrm{~min}$ after the start of combustion, and the air was left in the chamber for another $2 \mathrm{~min}$. Thus, the mice were exposed to the smoke for a total of $3 \mathrm{~min}$, followed by fresh air introduced by ventilation.

\section{Measurement of chemicals in XLR-11 smoke}

A 0.5 -g portion of XLR-11 containing herb was burned, and the resulting smoke was introduced to the inhalation chamber through the aerosol inlet. The airflow was stopped $60 \mathrm{~s}$ after the start of combustion, and then a $10 \mathrm{~mL}$ portion of the chamber air was extracted by a gas-tight syringe and absorbed in $1 \mathrm{~mL}$ methanol. The mixture was shaken in a hermetically sealed vial for $10 \mathrm{~min}$. The solvent was evaporated to dryness under a nitrogen stream, and the residue was dissolved in $100 \mu \mathrm{L}$ methanol. A $20 \mu \mathrm{L}$ portion of that mixture was analyzed by high-performance liquid chromatography (HPLC) using the SPD-M10A at $300 \mathrm{~nm}$ (Shimadzu Co., Kyoto, Japan) and a Prodigy $5 \mu$ ODS column $(150 \times 4.6 \mathrm{~mm}, 5 \mu \mathrm{m}$ particle size; Phenomenex, Torrance, CA, USA). Gradient elution was performed with (A) $10 \mathrm{mM}$ ammonium acetate and (B) acetonitrile at a flow rate of $1 \mathrm{~mL} / \mathrm{min}$. The initial elution condition was set at $50 \%$ $\mathrm{B}$ for $20 \mathrm{~min}$ and then changed to $100 \% \mathrm{~B}$ for $10 \mathrm{~min}$ [9].

\section{Drug treatment}

The mice were placed in an activity chamber $[200 \mathrm{~mm}$ (width) $\times 200 \mathrm{~mm}$ (depth) $\times 250 \mathrm{~mm}$ (height)] for $30 \mathrm{~min}$ prior to drug administration to allow them to become acclimated to the environment. AM-251, XLR-11, and XLR-11 degradant were dissolved in a 1:1 mixture of ethanol and Kolliphor ELP (BASF Japan, Tokyo, Japan) and diluted with saline to obtain an ethanol/Kolliphor ELP/ saline vehicle ratio of 1:1:98. Gabapentin was dissolved in saline and added to a 1:1 mixture of ethanol and Kolliphor ELP to obtain an ethanol/Kolliphor ELP/saline vehicle ratio of 1:1:98. Vehicle $(20 \mathrm{~mL} / \mathrm{kg})$, XLR-11 $(15 \mathrm{mg} /$ $\mathrm{kg})$, XLR-11 degradant (15 mg/kg), AM-251 (6 mg/kg), 
and gabapentin $(40 \mathrm{mg} / \mathrm{kg}$ ) were injected in the mice intraperitoneally (i.p.). The $\mathrm{CB}_{1}$ receptor antagonist AM-251 and gabapentin were administered $30 \mathrm{~min}$ before injecting XLR-11 degradant.

\section{Behavioral studies}

The mice were anesthetized with a combination of medetomidine $(0.15 \mathrm{mg} / \mathrm{kg})$, midazolam $(2 \mathrm{mg} / \mathrm{kg})$ and butorphanol $(2.5 \mathrm{mg} / \mathrm{kg}$ ). Nano-Tag (Kissei Comtec Co., Matsumoto, Japan), an apparatus that measures body temperature and locomotor activity, was implanted in the back of the mice at least $20 \mathrm{~h}$ before initiating the experiments. The locomotor activity determined by the Nano-Tag device was defined as cross count data, providing counts of the number of times crossing the threshold levels from bottom to top per recording interval for the waveform synthesized by the XYZ acceleration vectors [12]. The body temperature and locomotor activity were analyzed by the Nano-Tag viewer program (Kissei Comtec Co.). The bar test was used to measure the intensity of catalepsy. Briefly, the forepaws of the mice were placed on a metal bar (6 $\mathrm{mm}$ diameter) positioned horizontally at a height of $3.5 \mathrm{~cm}$. The time until the mice started to move was measured, and the maximum cutoff time was set at 90 or $180 \mathrm{~s}$.

\section{In vivo microdialysis for dopamine in the nucleus accumbens}

Mice, anesthetized with the combination of three anesthetics, were placed in a stereotaxic apparatus. A microdialysis probe (D-I-6-01: $0.22 \mathrm{~mm}$ outer diameter, $1 \mathrm{~mm}$ membrane length; Eicom Co., Ltd., Kyoto, Japan) was implanted into the nucleus accumbens at the following coordinates; AP: $+1.76 \mathrm{~mm}$, ML: $+0.5 \mathrm{~mm}$ relative to bregma and DV: $-5.0 \mathrm{~mm}$ from the skull. The probes were secured to the skull using dental acrylic. Mice were provided at least $20 \mathrm{~h}$ for recovery from surgery before initiating the experiments. The probes were perfused at $2 \mu \mathrm{L} / \mathrm{min}$ with artificial cerebrospinal fluid. Two hours after the reflux, the dialysate sample was collected in 10-min fractions. Three samples were obtained to establish the baseline levels of extracellular DA before drug administration, and six samples were obtained thereafter. DA levels were measured using an HTEC-500 HPLC system with an electrochemical detector (Eicom Co., Ltd.) and $\mathrm{a} \mathrm{C}_{18}$ reversed-phase column $(30 \times 4.6 \mathrm{~mm}$ i.d., Eicompak PP-ODS; Eicom Co., Ltd.) [13, 14]. After the microdialysis, the mice were sacrificed and their brains were histologically examined to validate the probe placement.

\section{In vivo measurement of extracellular glutamate in the hippocampus}

Changes in glutamate levels in the hippocampus were evaluated using an enzyme-based biosensor capable of monitoring real-time changes in neurochemical concentrations in the brains of freely moving animals (Pinnacle Technology Inc., Lawrence, KA, USA). Prior to measurement, the mice were anesthetized with sodium pentobarbital $(50 \mathrm{mg} / \mathrm{kg}$, i.p.) and were placed in a stereotaxic apparatus. A guide cannula was implanted in the hippocampus at the following coordinates: AP: $-2.7 \mathrm{~mm}$, ML: $+3.0 \mathrm{~mm}$ relative to bregma and DV: $-1.0 \mathrm{~mm}$ from the skull. To connect the biosensor to the amplifier for measurement, a head-mount device (\#8201; Pinnacle Technology Inc.) was placed around the recording point and an anchor screw was placed to fix the head-mount device. The guide cannula, the screw and the head-mount device were covered with dental acrylic. On the morning of the day of measurement, the biosensor was calibrated. Briefly, the biosensor was placed in a beaker with $20 \mathrm{~mL}$ phosphate-buffered saline ( $\mathrm{pH}$ 7.4), and the signal was measured. After obtaining a stable baseline, the analyte (5 mM glutamate stock solution) was injected until the glutamate concentration reached $40 \mu \mathrm{M}$. Interference solution (100 mM ascorbic acid stock solution) was then added to confirm the reaction. After calibration, the mice were anesthetized with ether, and the biosensor was inserted into the guide cannula and lowered into the recording position. After the sensor was connected to the amplifier, the preamplifier was plugged into the head-mount device, and the measurement was started. After obtaining a stable baseline of the glutamate signal for over $1 \mathrm{~h}$, XLR-11 degradant or vehicle was injected intraperitoneally, and the glutamate response in the hippocampus was recorded. Data analysis was conducted from $2.5 \mathrm{~min}$ before administration to $10 \mathrm{~min}$ after administration. Biosensor currents were collected at 10-s intervals, and the change in glutamate level from the baseline was measured. The baseline value was defined as the signal present $20 \mathrm{~s}$ before administration [11]. After each experiment, the brain was fixed with $4 \%$ paraformaldehyde and $30-\mu \mathrm{m}$ coronal sections were produced by a cryostat (Bright Instrument Company, Huntingdon, UK) to verify the biosensor position.

\section{Statistical analysis}

Body temperature and locomotor activity data were assessed using analysis of variance (ANOVA) followed by Tukey's test. The bar test data were analyzed using the Mann-Whitney test. Data from microdialysis experiments and extracellular glutamate levels were analyzed by Welch's $t$ test 
Fig. 3 XLR-11 smoke induced transient hyperreflexia (a) and hypothermia $(\mathbf{b})$ in mice. a Locomotor activity was measured every minute from $5 \mathrm{~min}$ before to $20 \mathrm{~min}$ after XLR-11 smoke exposure using an implanted Nano-Tag device. The vertical axis represents counts per minute (cpm) recorded by the three-axis sensor. b Body temperature was measured every minute from $5 \mathrm{~min}$ before to $40 \mathrm{~min}$ after XLR-11 smoke exposure using an implanted Nano-Tag device. Values represent the mean \pm standard error of the mean (SEM) $(n=6)$. Statistical analysis was performed using Tukey's test. * $p<0.05$, $* * p<0.01$ vs. control
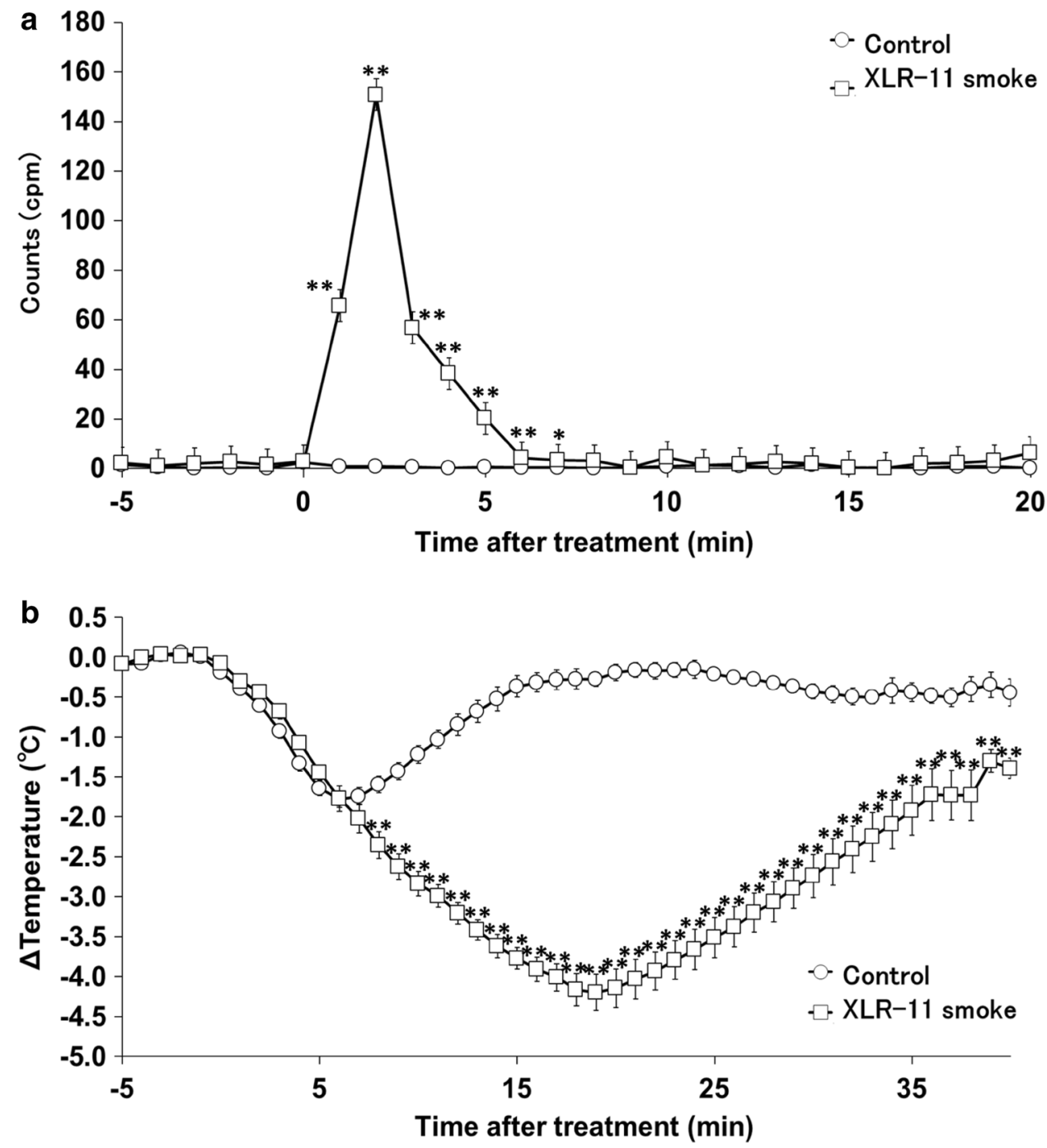

and two-way ANOVA followed by the Bonferroni test, respectively.

\section{Results}

\section{Changes in body temperature and behavior of mice exposed to XLR-11 smoke}

Mice were exposed to the smoke produced by burning the simulated herbal drug product containing the synthetic cannabinoid XLR-11 to observe its psychopharmacological effects. These effects were monitored using the implanted Nano-Tag device, which can detect movements in both vertical and horizontal directions. The mice that inhaled the herbal smoke containing no drug (control) showed no change in their behavior. In contrast, the mice that inhaled the drug-containing smoke showed excitatory and/or hyperreflexic behavior, such as jumping at the very early phase of exposure, followed by suppressive behavior. A significant increase in the locomotor activity, which mainly comprised vertical movements such as jumping, was observed from 1 to $7 \mathrm{~min}$ after XLR-11 smoke exposure (Fig. 3a).

The control mice showed a slight decrease in body temperature over a 5-min period after smoke exposure (Fig. 3b). The herbal smoke was introduced into the test cage where a mouse was placed in at a flow rate of $18 \mathrm{~L} / \mathrm{min}$ for $1 \mathrm{~min}$. The flow was stopped for 2 min to expose the mouse to the smoke. The smoke in the cage was replaced by flesh air over the next $2 \mathrm{~min}$, and the chamber lid was then opened. Therefore, a mouse was exposed with the airflow for the first $1 \mathrm{~min}$ and last $2 \mathrm{~min}$ during $5 \mathrm{~min}$-exposure in the lidded cage. Such air blowing may decrease the body temperature. The body temperature recovered to the basal level within the next $10 \mathrm{~min}$ under the circumstances without the airflow (Fig. 3b). The mice that inhaled the drug-containing smoke showed a significant and a sustainable decrease in the body 
temperature starting $7 \mathrm{~min}$ after exposure, and the effect was most intense after $20 \mathrm{~min}$ and lasted for at least $40 \mathrm{~min}$ (Fig. 3b). These results indicated that the XLR-11 smoke induced an excitatory and hyperreflexic effect at the beginning of exposure followed by hypothermia and hypomobility, which are characteristic effects of synthetic cannabinoids [15-17].

\section{XLR-11 smoke contains XLR-11 degradant as a main ingredient}

Reportedly, XLR-11 undergoes a pyrolytic change in its chemical structure involving an asymmetric ring opening in its tetramethyl cyclopropane ring (Fig. 1a,b) [18]. Therefore, experiments were conducted to determine the chemicals present in the XLR-11 smoke. The XLR-11 smoke was absorbed in methanol and subjected to HPLC analysis (Fig. 4c). Two peaks were observed (peaks A and B); retention time of peak A was considered to be equivalent to that of the XLR-11 degradant (Fig. 4b), and peak B was identical to that of XLR-11 (Fig. 4a). The calibration curve of XLR11 showed linearity between 20 and $200 \mathrm{ng}$, with a correlation coefficient $(r)>0.999$ and regression line $y=57000 x$. The calibration curve of the XLR-11 degradant showed linearity between 200 and $8000 \mathrm{ng}$, with $r>0.999$ and regression line $y=31700 x$. These analytical parameters supported the quantitative reproducibility. By quantitative analysis, the concentrations of XLR-11 and its degradant were calculated to be 63.8 and $1640 \mathrm{ng} / \mathrm{cm}^{3}$, respectively, indicating that the XLR-11 smoke contained XLR-11 and XLR-11 degradant at a ratio of approximately 1:25.

\section{Effects of XLR-11 and XLR-11 degradant on body temperature and behavior in mice}

To clarify whether the excitatory effect of the XLR-11 smoke in mice is attributed to XLR-11 or XLR-11 degradant, mice were administered XLR-11 degradant i.p. at a dose equivalent to that used in the inhalation experiment, and the effect was compared with that of the parent compound. Mice treated with XLR-11 degradant $(15 \mathrm{mg} / \mathrm{kg}$, i.p.) showed excitatory behavior such as jumping at the beginning of the treatment, but mice treated with XLR-11 at a dose equivalent to the degradant $(15 \mathrm{mg} / \mathrm{kg}$, i.p.) showed no such behavior. A significant increase in the locomotor activity was observed between 2 and 4 min after XLR-11 degradant treatment (Fig. 5a) similar to that after XLR-11 smoke exposure. XLR-11 and XLR-11 degradant induced akinesia, determined by the bar test, in mice. Although no significant difference was observed between XLR-11 and XLR-11 degradant in this experiment when the test duration was set at $90 \mathrm{~s}$, the immobility lasted for at least $120 \mathrm{~min}$ after the treatment (Fig. 5b). XLR-11 showed a significant decrease in the body temperature, starting 5 min after the treatment and lasting for $90 \mathrm{~min}$. XLR-11 degradant induced more potent hypothermia than XLR-11; significant differences between these compounds were observed at $5 \mathrm{~min}$, $30 \mathrm{~min}$ or later (Fig. 5c). These results suggest that both the excitatory and suppressive effects of the XLR-11 smoke were mainly caused by XLR-11 degradant.

\section{$\mathrm{CB}_{1}$ mediates XLR-11 degradant-induced changes in physical responses}

Mice were pretreated with the $\mathrm{CB}_{1}$ receptor antagonist AM-251 and treated with XLR-11 degradant to investigate the involvement of the $\mathrm{CB}_{1}$ receptor in the XLR-11 degradant-induced excitatory behavior. An increase in the locomotor activity observed 1-4 min after XLR-11 degradant treatment was significantly suppressed by AM-251 (Fig. 6a). In addition, AM-251 almost completely suppressed the immobility (Fig. 6b) and hypothermia (Fig. 6c) induced by the XLR-11 degradant. These results indicate that the $\mathrm{CB}_{1}$ receptor is involved not only in hypothermia and akinesia but also in the excitatory behavior induced by the XLR-11 degradant.

\section{Effect of XLR-11 degradant on dopamine levels in the nucleus accumbens in mice}

DA levels in the nucleus accumbens were measured using in vivo microdialysis to investigate whether dopaminergic transmission is involved in the excitatory effect of XLR-11 degradant. Mice were treated i.p. with XLR-11 degradant or vehicle, and the extracellular DA levels were determined at 10-min intervals. The XLR-11 degradant significantly increased the DA levels in the nucleus accumbens between 10 and 20 min after the treatment (Fig. 7a). However, the time when DA levels increased did not coincide with the time when the excitatory behavior was observed. Pretreatment with the DA $D_{1}$ receptor antagonist SCH23390 $(50 \mu \mathrm{g} /$ $\mathrm{kg}$, i.p.) or the $\mathrm{DA} \mathrm{D}_{2}$ receptor antagonist sulpiride $(50 \mathrm{mg} /$ $\mathrm{kg}$, i.p.), which have been shown to suppress synthetic cathinone-induced psychoactive effects [13], showed no effect on the excitatory action of XLR-11 degradant (Fig. 7b). These findings suggest that dopaminergic transmission does not play a major role in the XLR-11 degradant-induced excitatory behavior.

\section{Effect of XLR-11 degradant on glutamate levels in the hippocampus}

Glutamate levels in the hippocampus were measured in vivo using an enzyme biosensor to investigate whether excessive glutamatergic transmission is involved in the excitatory effect of XLR-11 degradant. A decrease, in contrast to increase, was 
Fig. 4 High-performance liquid chromatography (HPLC) chromatograms of XLR-11 (a),

XLR-11 degradant (b), and chamber air (c). XLR-11 (a,

$200 \mathrm{ng}$ ) and XLR-11 degradant (b, $200 \mathrm{ng}$ ) were analyzed by HPLC at $300 \mathrm{~nm}$. A $10 \mathrm{~mL}$ portion of chamber air was absorbed in methanol and analyzed by HPLC (c) a

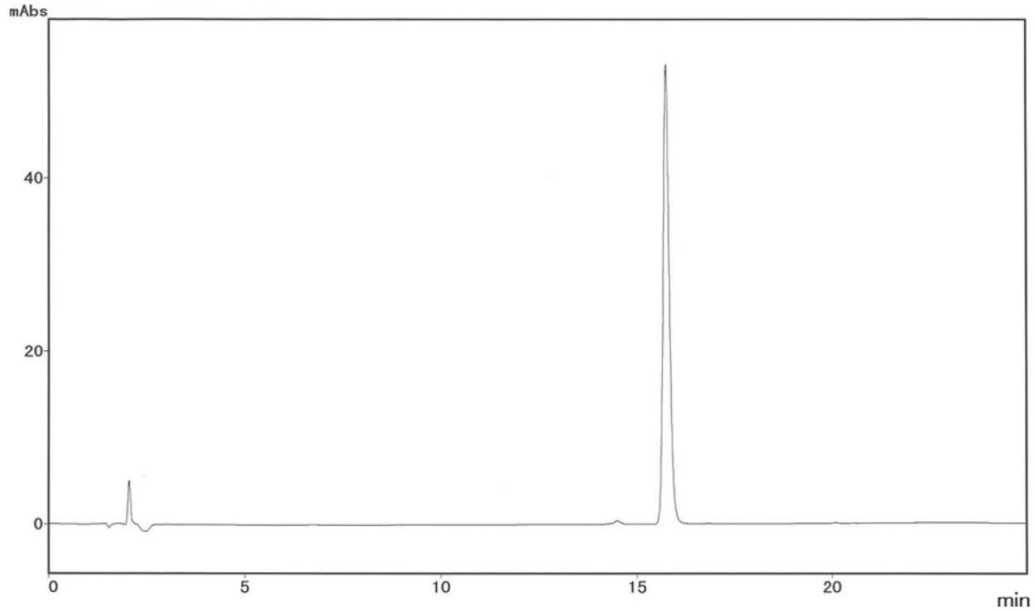

b

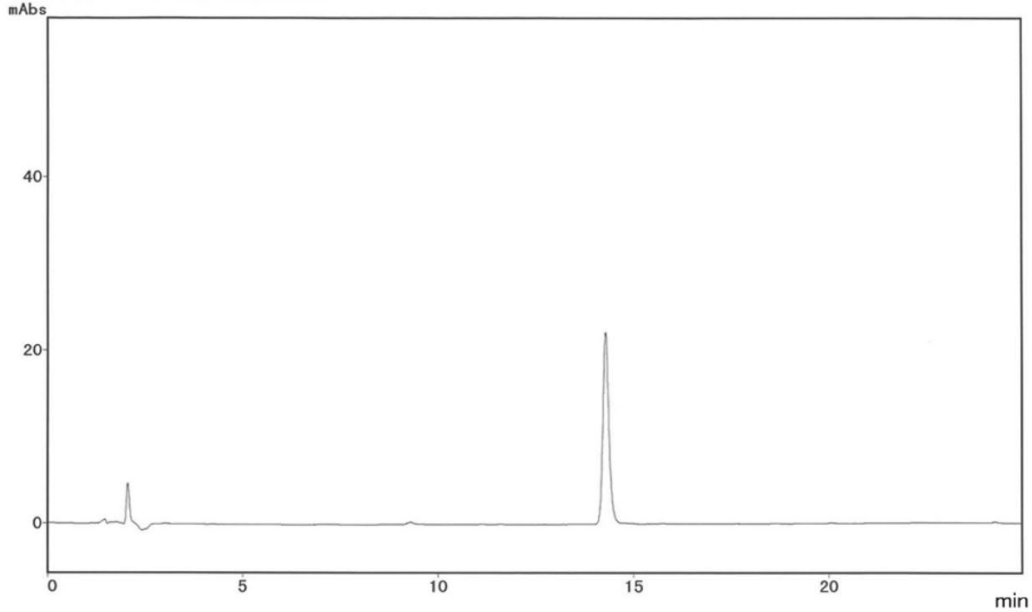

C

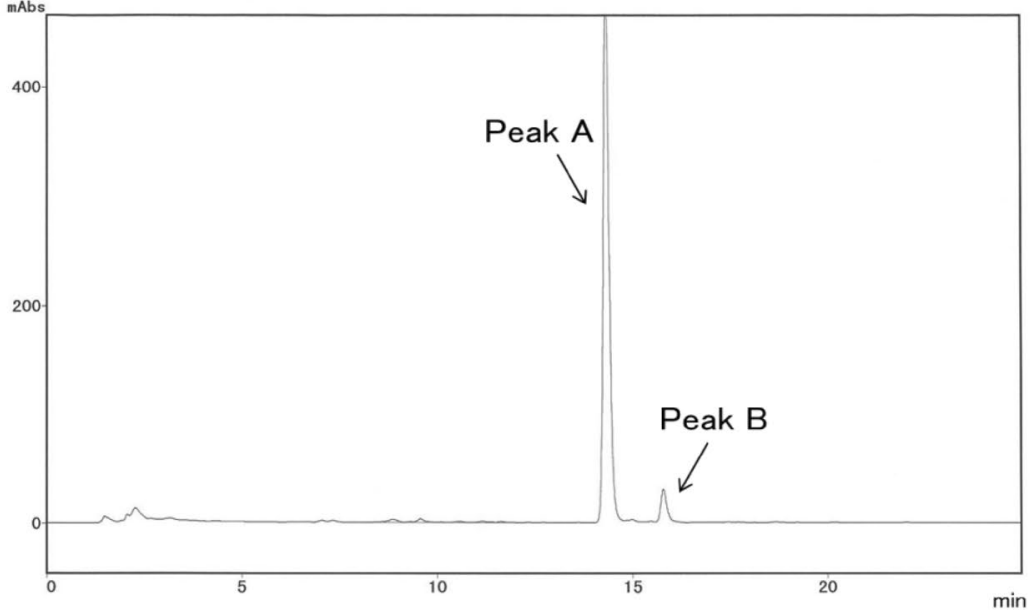

observed in the extracellular glutamate levels after XLR-11 degradant treatment (Fig. 7c). In addition, pretreatment with the glutamate receptor (mGlu5) antagonist SIB1757 (4 mg/ $\mathrm{kg}$, i.p.), which has been shown to suppress AM-2201-induced seizures [11], showed almost no effect on the excitatory action of XLR-11 degradant (Fig. 7d). These results suggest that glutamatergic transmission does not play a major role in the XLR-11 degradant-induced excitatory behavior. 

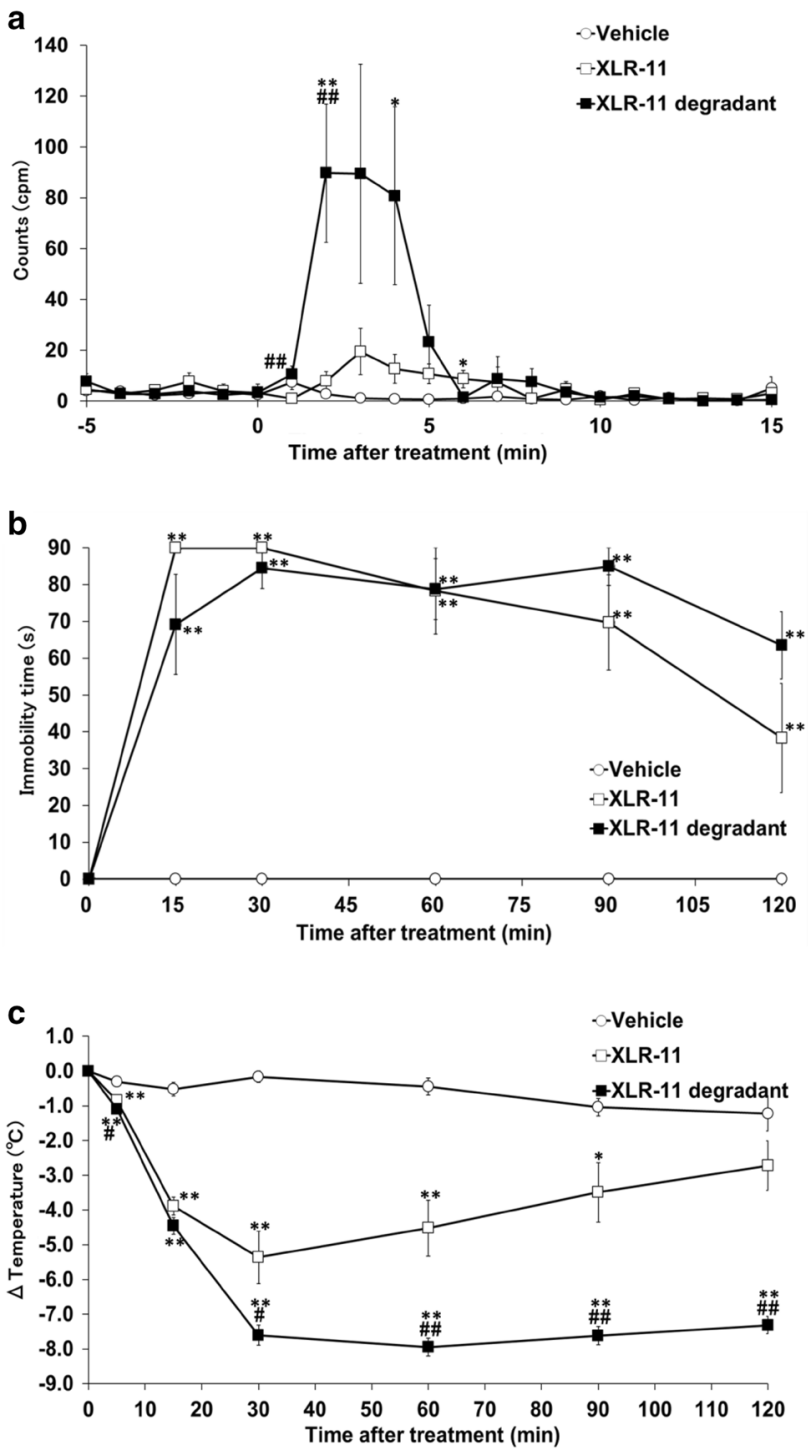

Fig. 5 Effects of XLR-11 and XLR-11 degradant on locomotor activity (a), catalepsy (b), and body temperature (c) in mice. Mice were intraperitoneally (i.p.) treated with vehicle (open circle), XLR-11 (15 mg/kg, open square), or XLR-11 degradant (15 mg/kg, closed square). a Locomotor activity was measured from $5 \mathrm{~min}$ before to 15 min after administration using an implanted Nano-Tag device. b The bar test was performed before and 15, 30, 60, 90 and 120 min after administration. c Body temperature was measured before and 5, $15,30,60,90$ and $120 \mathrm{~min}$ after administration using an implanted Nano-Tag device. Values represent the mean \pm SEM $(n=6)$. Statistical analysis was performed using Tukey's test $(\mathbf{a}, \mathbf{c})$ or the Mann-Whitney test (b). ${ }^{*} p<0.05,{ }^{*} p<0.01$ vs. vehicle. ${ }^{*} p<0.05$, ${ }^{\#} p<0.01$ vs. XLR-11

\section{Effects of gabapentin on XLR-11 degradant-induced transient behavior}

Next, a series of experiments were conducted to investigate the involvement of GABAergic transmission using gabapentin, which increases and maintains the
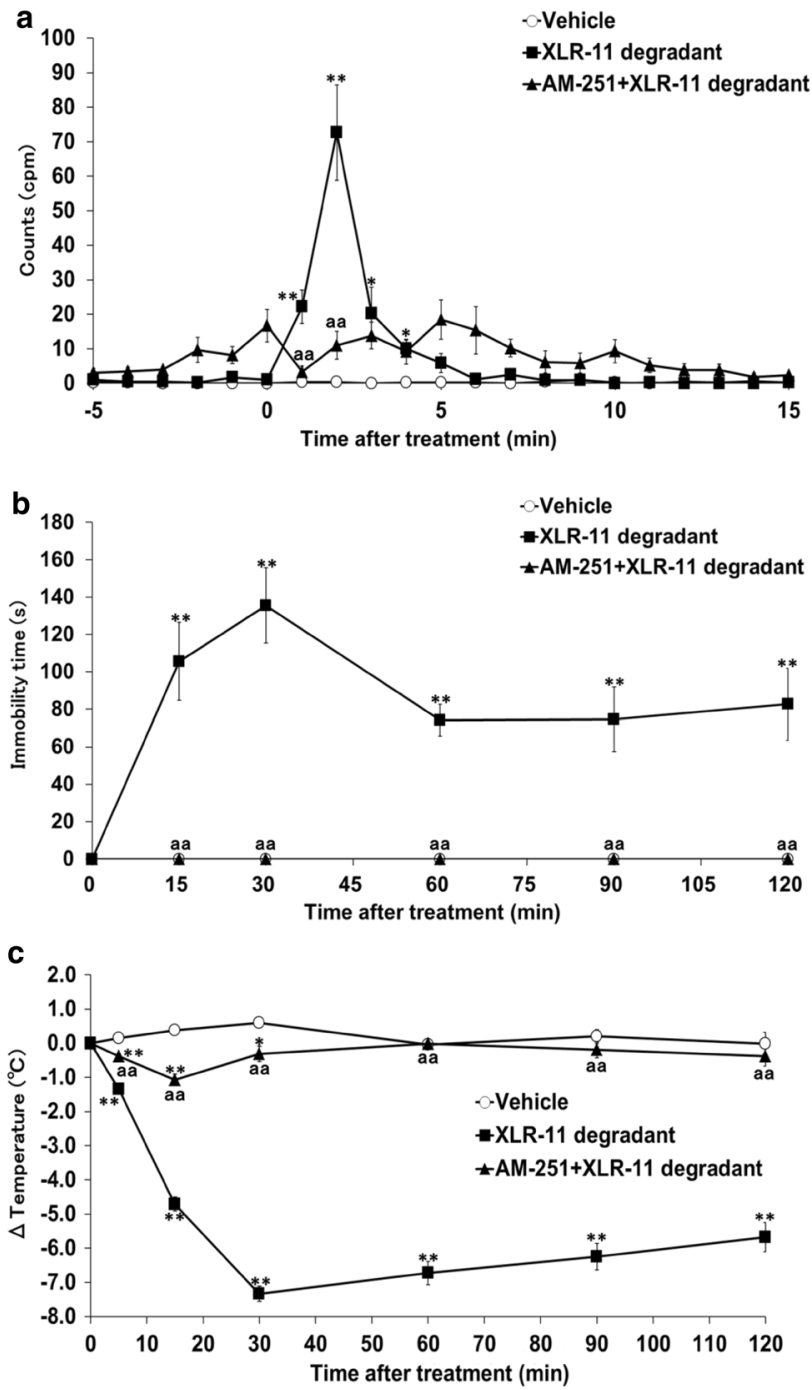

Fig. 6 Effects of AM-251 on XLR-11 degradant-induced transient hyperreflexia (a), catalepsy (b), and hypothermia (c). AM-251 (6 mg/ $\mathrm{kg}$, i.p.) was administered $30 \mathrm{~min}$ before injection of XLR-11 degradant $(15 \mathrm{mg} / \mathrm{kg}$, i.p.). Values represent the mean \pm SEM $(n=6)$. Statistical analysis was performed using Tukey's test $(\mathbf{a}, \mathbf{c})$ or the MannWhitney test (b). ${ }^{*} p<0.05$ and ${ }^{* *} p<0.01$ vs. vehicle. ${ }^{\text {aa }} p<0.01$ vs. XLR-11 degradant

GABAergic neuronal function along with inhibiting the voltage-dependent calcium channel. Reportedly, gabapentin suppresses pentylenetetrazol-induced seizures at a dose of $20 \mathrm{mg} / \mathrm{kg}$ (i.p.) [19] and audiogenic seizures at doses of 30,40 , and $50 \mathrm{mg} / \mathrm{kg}$ (i.p.) [20]. Therefore, gabapentin at a dose of $40 \mathrm{mg} / \mathrm{kg}$ (i.p.) was administered $30 \mathrm{~min}$ before XLR-11 degradant treatment, and the locomotor activity was measured. Gabapentin significantly inhibited the XLR-11 degradant-induced excitatory behavior between 2 and 3 min after treatment (Fig. 7e), although the inhibitory effect seemed to be incomplete. These results suggest that impaired GABAergic transmission 

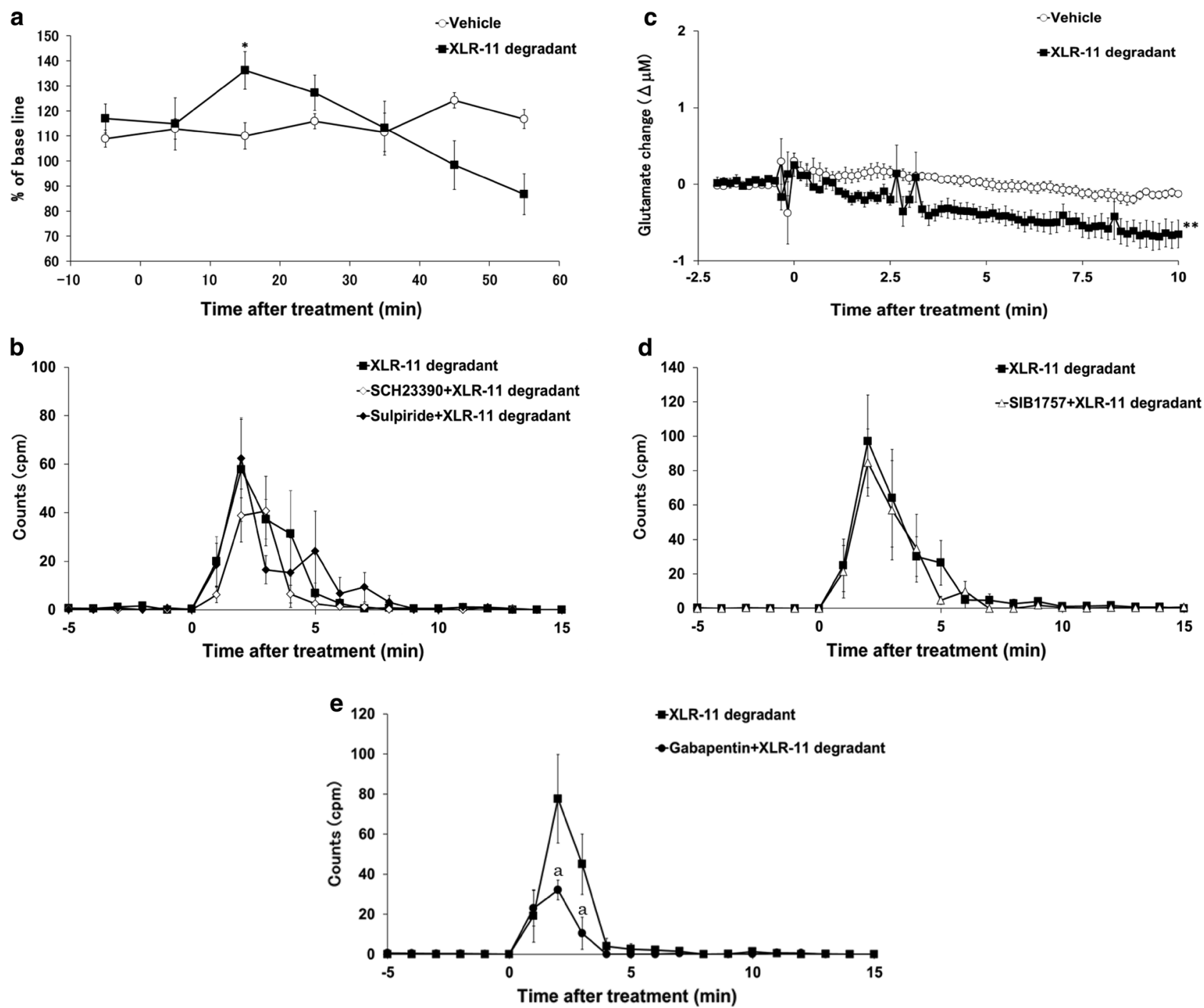

Fig. 7 Neurotransmission involved in XLR-11 degradant-induced transient hyperreflexia. a Mice were administered XLR-11 degradant $(15 \mathrm{mg} / \mathrm{kg}$, i.p.) or vehicle $(10 \mathrm{~mL} / \mathrm{kg}$, i.p. $)$ at $0 \mathrm{~min}$, and the dialysate was collected every $10 \mathrm{~min}$ for $60 \mathrm{~min}$. Extracellular dopamine (DA) levels in the nucleus accumbens were analyzed by HPLC-electrochemical detection. Basal values of extracellular DA levels in the nucleus accumbens were $1.46 \pm 0.25 \mathrm{nM}(n=9)$. Values represent the percentage changes (the mean \pm SEM, $n=4-5$ ) from the basal levels. Statistical analysis was performed using the Welch's test. $* p<0.05$ vs. vehicle. b Mice were pretreated with SCH23390 (50 $\mu \mathrm{g} / \mathrm{kg}$, i.p. $)$ or sulpiride $(50 \mathrm{mg} / \mathrm{kg}$, i.p.), and treated with XLR-11 degradant $(15 \mathrm{mg} / \mathrm{kg})$. Locomotor activity was measured from $5 \mathrm{~min}$ before to

and/or calcium-mediated signal transmission could be involved, at least in part, in the excitatory effect of XLR11 degradant.
15 min after XLR-11 degradant using an implanted Nano-Tag device. c Mice were administered XLR-11 degradant $(15 \mathrm{mg} / \mathrm{kg})$ or vehicle at 0 min. Biosensor currents reflecting glutamate levels were obtained every $10 \mathrm{~s}$ from $2.5 \mathrm{~min}$ before to $10 \mathrm{~min}$ after administration. Values represent the mean \pm SEM $(n=4)$. Statistical analysis was performed using the Bonferroni test. $* * p<0.01$ vs. vehicle. d, e Mice were pretreated with SIB1757 (4 mg/kg, i.p., d) or gabapentin $(40 \mathrm{mg} / \mathrm{kg}$, i.p., e) and treated with XLR-11 degradant $(15 \mathrm{mg} / \mathrm{kg})$. Locomotor activity was measured from $5 \mathrm{~min}$ before to $15 \mathrm{~min}$ after administration. Values represent the mean \pm SEM $(n=5-6) .{ }^{\mathrm{a}} p<0.05$ vs. XLR-11 degradant

\section{Discussion}

Some synthetic cannabinoids were reported to induce a generalized seizure in drug abusers immediately after smoking [21]. These compounds impart nonselective agonistic effects on centrally and peripherally located $\mathrm{CB}_{1}$ and $\mathrm{CB}_{2}$ receptors, although psychoactive effects are mainly mediated via the $\mathrm{CB}_{1}$ receptor. A recent study 
demonstrated that $\Delta^{9}$-THC and JWH-018 induced seizures in mice via the $\mathrm{CB}_{1}$ receptor [22]. It has been reported that i.p. injection of XLR-11 causes hypothermia, suppression of locomotor activity and induction of catalepsy in mice $[23,24]$. On the other hand, it has not been reported that XLR-11 exhibits excitatory action. In the present study, inhalation of the XLR-11 smoke by mice stimulated locomotor activity such as jumping, which is known as the "popcorn effect" observed after $\Delta^{9}$-THC treatment [25]. In addition, the main psychoactive component in the XLR-11 smoke was found to be XLR-11 degradant produced by pyrolysis. The stimulated psychomotor function could be likened to the seizures in humans $[26,27]$ and has been shown to be associated with electrographic seizures in mice [22]. Therefore, XLR-11 degradant produced during smoking may cause seizures in mice and possibly in humans as well. It is suggested that the previous studies underestimated XLR-11 potency which would increase by smoking. This study shows the importance of experimental design in line with the actual situation of human abuse. The present study also demonstrated that the excitatory effect of XLR-11 degradant was mediated mainly through the $\mathrm{CB}_{1}$ receptor, a result consistent with that reported by Malyshevskaya et al. [22]. UR-144 (Fig. 1c) is a synthetic cannabinoid containing the cyclopropyl ring that forms an open ring structure when subjected to pyrolysis [9]. In the previous study, this UR-144 degradant (Fig. 1d) also showed excitatory effect at the beginning of administration, and displayed 4-fold higher agonistic activity on the $\mathrm{CB}_{1}$ receptor than UR-144 [9]. Therefore, smoking certain synthetic cannabinoids leads to greater psychoactive effects than inhaling their respective parent compounds.

The synthetic cannabinoids JWH-250 and JWH-073 cause hyperreflexia and elevated DA levels in the nucleus accumbens after administration [10]. Based on this finding, DA levels in the nucleus accumbens after XLR-11 degradant administration were measured in the present study by microdialysis. The results showed that the onset of excitatory behavior did not coincide with the time of increase in DA levels (Fig. 7a). These results suggest that an increase in DA levels in the nucleus accumbens is not involved in the excitatory effect of XLR-11 degradant. Reportedly, the synthetic cannabinoid AM-2201 causes seizures in mice in the early course of treatment when glutamate levels in the hippocampus increase significantly [11]. However, in the present study, glutamate levels in the hippocampus decreased significantly after XLR-11 degradant administration (Fig. 7c). This result suggests that the excitatory effect of XLR-11 degradant is caused by a mechanism not mediated by glutamate.

This study also demonstrated that gabapentin significantly suppressed the enhanced locomotor activity induced by XLR-11 degradant (Fig. 7e). The general mechanisms underlying the action of gabapentin are as follows: (1) it inhibits the release of excitatory neurotransmitters such as glutamate, by suppressing the influx of calcium via binding to the $\alpha 2 \delta-1$ auxiliary subunit of the voltage-dependent calcium channel expressed on the presynapse of the excitatory nervous system, and (2) it increases the extracellular GABA concentration in the brain cortex and activates GABA transporter to maintain/enhance GABAergic function [20, 28]. In this study, because glutamate levels in the hippocampus significantly decreased, instead of increasing, after XLR-11 degradant administration, suppressed GABAergic function may be involved in the excitatory effect of XLR-11 degradant. $\mathrm{CB}_{1}$ receptor stimulation has been shown to increase $\mathrm{Ca}^{2+}$ concentration in smooth muscle cells in culture [29]. In addition, increased postsynaptic $\mathrm{Ca}^{2+}$ levels have been shown to ultimately cause a transient reduction in the release of GABA from $\mathrm{CB}_{1}$-expressing interneurons [30]. These findings suggest that XLR-11 degradant cause a transient suppression of GABAergic function in a $\mathrm{CB}_{1}$ receptordependent manner [31]. Although the overall mechanism of synthetic cannabinoid-mediated seizures or excitatory action is still unclear, $\mathrm{CB}_{1}$ receptor-dependent neurotransmission and possibly the GABAergic function are likely involved in the transient hyperreflexic behavior.

\section{Conclusions}

In conclusion, our results indicate that the inhalation of XLR-11 smoke, the main active component of which is XLR-11 degradant, causes hyperreflexia as well as hypothermia and catalepsy in mice. The XLR-11 degradant is more potent than XLR-11, demonstrating the importance of this study in line with the actual situation of human abuse. This finding further suggests that the hyperreflexic effect of XLR-11 degradant is mediated through the $\mathrm{CB}_{1}$ receptor and possibly GABAergic function.

Acknowledgements The authors are grateful to Mr. Kazuo Kanazawa (InLabTech Japan LLC., Japan) and Mr. Masahiro Tamura (Sibata Scientific Technology Ltd., Japan) for development of the multipurpose inhalation cage unit, and Dr. Yuki Odanaka (Division of Bioanalytical Chemistry, Showa University School of Pharmacy, Japan) for manipulation of NMR. This work was supported by a Showa University Research Grant for Young Researchers.

\section{Compliance with ethical standards}

Conflict of interest The authors declare that there is no conflict of interest.

Ethical approval All procedures for animal care were conducted in accordance with the National Institutes of Health Guide for the Care and Use of Laboratory Animals and were approved by the Institutional 
Animal Care and Use Committee at the Showa University. Every effort was made to minimize the number of animals used and their sufferings.

Open Access This article is distributed under the terms of the Creative Commons Attribution 4.0 International License (http://creativeco mmons.org/licenses/by/4.0/), which permits unrestricted use, distribution, and reproduction in any medium, provided you give appropriate credit to the original author(s) and the source, provide a link to the Creative Commons license, and indicate if changes were made.

\section{References}

1. Florek-Luszczki M, Wlaz A, Zagaja M, Andres-Mach M, Kondrat-Wrobel MW, Luszczki JJ (2015) Effects of WIN 55,212-2 (a synthetic cannabinoid $\mathrm{CB}_{1}$ and $\mathrm{CB}_{2}$ receptor agonist) on the anticonvulsant activity of various novel antiepileptic drugs against $6 \mathrm{~Hz}$-induced psychomotor seizures in mice. Pharmacol Biochem Behav 130:53-58. https://doi.org/10.1016/j.pbb.2015.01.003

2. Gilbert MT, Sulik KK, Fish EW, Baker LK, Dehart DB, Parnell SE (2016) Dose-dependent teratogenicity of the synthetic cannabinoid CP-55,940 in mice. Neurotoxicol Teratol 58:15-22. https ://doi.org/10.1016/j.ntt.2015.12.004

3. Numazawa $S$ (2013) The forefront of drug abuse-recent trends in illegal drug markets in Japan, 2012. Showa Univ J Pharm Sci 4:13-25 (in Japanese with English abstract)

4. National Institute on Drug Abuse (2018) Synthetic cannabinoids (K2/Spice). https://www.drugabuse.gov/publications/drugfacts/ synthetic-cannabinoids-k2spice. Accessed 28 Dec 2018

5. World Health Organization (2016) XLR-11: critical review report. Agenda item 4.12. https://www.who.int/medicines/access/contr olled-substances/4.12_XLR-11_CritReview.pdf?ua=1. Accessed 9 Apr 2019

6. Scientific Working Group for the Analysis of Seized Drugs (2014) XLR-11. http://www.swgdrug.org/Monographs/XLR11.pdf. Accessed 5 Apr 2019

7. Kanamori T, Kanda K, Yamamuro T, Kuwayama K, Tsujikawa K, Togawa Y, Inoue H (2015) Detection of main metabolites of XLR-11 and its thermal degradation product in human hepatoma HepaRG cells and human urine. Drug Test Anal 7:341-345. https ://doi.org/10.1002/dta.1765

8. Kemp AM, Clark MS, Dobbs T, Galli R, Sherman J, Cox R (2016) Top 10 facts you need to know about synthetic cannabinoids: not so nice spice. Am J Med 129:240-244. https://doi.org/10.1016/j. amjmed.2015.10.008

9. Kaizaki-Mitsumoto A, Hataoka K, Funada M, Odanaka Y, Kumamoto H, Numazawa S (2017) Pyrolysis of UR-144, a synthetic cannabinoid, augments an affinity to human $\mathrm{CB}_{1}$ receptor and cannabimimetic effects in mice. J Toxicol Sci 42:335-341. https ://doi.org/10.2131/jts.42.335

10. Ossato A, Canazza I, Trapella C, Vincenzi F, De Luca MA, Rimondo C, Varani K, Borea PA, Serpelloni G, Marti M (2016) Effect of JWH-250, JWH-073 and their interaction on "tetrad", sensorimotor, neurological and neurochemical responses in mice. Prog Neuropsychopharmacol Biol Psychiatry 67:31-50. https:// doi.org/10.1016/j.pnpbp.2016.01.007

11. Funada M, Takebayashi-Ohsawa M (2018) Synthetic cannabinoid AM2201 induces seizures: involvement of cannabinoid $\mathrm{CB}_{1}$ receptors and glutamatergic transmission. Toxicol Appl Pharmacol 338:1-8. https://doi.org/10.1016/j.taap.2017.10.007

12. Yoshizawa T, Shimada S, Takizawa Y, Makino T, Kanada Y, Ito Y, Ochiai T, Matsumoto K (2019) Continuous measurement of locomotor activity during convalescence and acclimation in group-housed rats. Exp Anim. https://doi.org/10.1538/expan im.18-0097

13. Kaizaki A, Tanaka S, Numazawa S (2014) New recreational drug 1-phenyl-2-(1-pyrrolidinyl)-1-pentanone (alpha-PVP) activates central nervous system via dopaminergic neuron. J Toxicol Sci 39:1-6 (PMID:24418703)

14. Hataoka K, Kaizaki-Mitsumoto A, Numazawa S (2017) AlphaPVP induces the rewarding effect via activating dopaminergic neuron. J Toxicol Sci 42:539-543. https://doi.org/10.2131/ jts. 42.539

15. Wiley JL, Martin BR (2003) Cannabinoid pharmacological properties common to other centrally acting drugs. Eur J Pharmacol 471:185-193. https://doi.org/10.1016/S0014-2999(03)01856-9

16. Vigolo A, Ossato A, Trapella C, Vincenzi F, Rimondo C, Seri C, Varani K, Serpelloni G, Marti M (2015) Novel halogenated derivates of JWH-018: behavioral and binding studies in mice. Neuropharmacology 95:68-82. https://doi.org/10.1016/j.neuro pharm.2015.02.008

17. Wiley JL, Marusich JA, Lefever TW, Antonazzo KR, Wallgren MT, Cortes RA, Patel PR, Grabenauer M, Moore KN, Thomas BF (2015) AB-CHMINACA, AB-PINACA, and FUBIMINA: affinity and potency of novel synthetic cannabinoids in producing $\Delta^{9}$ tetrahydrocannabinol-like effects in mice. J Pharmacol Exp Ther 354:328-339. https://doi.org/10.1124/jpet.115.225326

18. Amaratunga P, Thomas C, Lemberg BL, Lemberg D (2014) Quantitative measurement of XLR11 and UR-144 in oral fluid by LCMS-MS. J Anal Toxicol 38:315-321. https://doi.org/10.1093/jat/ bku040

19. Kumar A, Lalitha S, Mishra J (2014) Hesperidin potentiates the neuroprotective effects of diazepam and gabapentin against pentylenetetrazole-induced convulsions in mice: possible behavioral, biochemical and mitochondrial alterations. Indian J Pharmacol 46:309-315. https://doi.org/10.4103/0253-7613.132180

20. De Sarro G, Spagnolo C, Gareri P, Gallelli L, De Sarro A (1998) Gabapentin potentiates the antiseizure activity of certain anticonvulsants in DBA/2 mice. Eur J Pharmacol 349:179-185 (PMID:9671096)

21. Hermanns-Clausen M, Müller D, Kithinji J, Angerer V, Franz F, Eyer F, Neurath H, Liebetrau G, Auwärter V (2018) Acute side effects after consumption of the new synthetic cannabinoids $\mathrm{AB}$ CHMINACA and MDMB-CHMICA. Clin Toxicol 56:404-411. https://doi.org/10.1080/15563650.2017.1393082

22. Malyshevskaya O, Aritake K, Kaushik MK, Uchiyama N, Cherasse Y, Kikura-Hanajiri R, Urade Y (2017) Natural $\left(\Delta^{9}\right.$-THC) and synthetic (JWH-018) cannabinoids induce seizures by acting through the cannabinoid $\mathrm{CB}_{1}$ receptor. Sci Rep 7:10516. https:// doi.org/10.1038/s41598-017-10447-2

23. Banister SD, Stuart J, Kevin RC, Edington A, Longworth M, Wilkinson SM, Beinat C, Buchanan AS, Hibbs DE, Glass M, Connor M, McGregor IS, Kassiou M (2015) Effects of bioisosteric fluorine in synthetic cannabinoid designer drugs JWH-018, AM-2201, UR-144, XLR-11, PB-22, 5F-PB-22, APICA, and STS135. ACS Chem Neurosci 6:1445-1458. https://doi.org/10.1021/ acschemneuro.5b00107

24. Gatch MB, Forster MJ (2015) $\Delta^{9}$-Tetrahydrocannabinol-like effects of novel synthetic cannabinoids found on the gray market. Behav Pharmacol 26:460-468. https://doi.org/10.1097/FBP.00000 00000000150

25. Adams IB, Martin BR (1996) Cannabis: pharmacology and toxicology in animals and humans. Addiction 91:1585-1614 (PMID:8972919)

26. Simmons JR, Skinner CG, Williams J, Kang CS, Schwartz MD, Wills BK (2011) Intoxication from smoking "spice". Ann Emerg Med 57:187-188. https://doi.org/10.1016/j.annemergme d.2010.08.039 
27. Monte AA, Calello DP, Gerona RR, Hamad E, Campleman SL, Brent J, Wax P, Carlson RG, ACMT Toxicology Investigators Consortium (ToxIC) (2017) Characteristics and treatment of patients with clinical illness due to synthetic cannabinoid inhalation reported by medical toxicologists: a ToxIC database study. J Med Toxicol 13:146-152. https://doi.org/10.1007/s1318 1-017-0605-9

28. Whitworth TL, Quick MW (2001) Upregulation of $\gamma$-aminobutyric acid transporter expression: role of alkylated gamma-aminobutyric acid derivatives. Biochem Soc Trans 29:736-741 (PMID: 11709066)

29. Filipeanu CM, de Zeeuw D, Nelemans SA (1997) $\Delta^{9}$ Tetrahydrocannabinol activates $\left[\mathrm{Ca}^{2+}\right]_{\mathrm{i}}$ increases partly sensitive to capacitative store refilling. Eur J Pharmacol 336:R1-R3. https ://doi.org/10.1016/S0014-2999(97)01254-5
30. Földy C, Neu A, Jones MV, Soltesz I (2006) Presynaptic, activitydependent modulation of cannabinoid type 1 receptor-mediated inhibition of GABA release. J Neurosci 26:1465-1469. https:// doi.org/10.1523/JNEUROSCI.4587-05.2006

31. Nyíri G, Cserép C, Szabadits E, Mackie K, Freund TF (2005) CB cannabinoid receptors are enriched in the perisynaptic annulus and on preterminal segments of hippocampal GABAergic axons. Neuroscience 136:811-822. https://doi.org/10.1016/j.neuroscien ce.2005.01.026

Publisher's Note Springer Nature remains neutral with regard to jurisdictional claims in published maps and institutional affiliations. 